\title{
Transparent micro- and nanopatterned poly(lactic acid) for biomedical applications
}

\author{
Christopher A. Mills, ${ }^{1}$ Melba Navarro, ${ }^{2}$ Elisabeth Engel, ${ }^{2}$ Elena Martinez, ${ }^{1}$ Maria Pau Ginebra, ${ }^{2}$ \\ Josep Planell, ${ }^{2}$ Abdelhamid Errachid, ${ }^{1}$ Josep Samitier ${ }^{1}$ \\ ${ }^{1}$ Centre of Reference for Bioengineering in Catalonia (CREBEC), Laboratory of Nanobioengineering, Barcelona Science \\ Park, C/Josep Samitier 1-5, 08028 Barcelona, Spain \\ ${ }^{2}$ Centre of Reference for Bioengineering in Catalonia (CREBEC), Biomaterials and Biomechanics Division, Department \\ of Materials Science and Metallurgy, Technical University of Catalonia, Avda. Diagonal 647, 08028 Barcelona, Spain
}

Received 10 September 2004; revised 8 July 2005; accepted 11 July 2005

Published online 12 December 2005 in Wiley InterScience (www.interscience.wiley.com). DOI: 10.1002/jbm.a.30539

\begin{abstract}
The formation of structures in poly(lactic acid) has been investigated with respect to producing areas of regular, superficial features with dimensions comparable to those of cells or biological macromolecules. Nanoembossing, a novel method of pattern replication in polymers, has been used for the production of features ranging from tens of micrometers, covering areas up to $1 \mathrm{~cm}^{2}$, down to hundreds of nanometers. Both micro- and nanostructures are faithfully replicated. Contact-angle measurements suggest that positive microstructuring of the polymer (where features protrude from the polymer surface) produces a more hydro-
\end{abstract}

philic surface than negative microstructuring. The ability to structure the surface of the poly(lactic acid), allied to the polymer's postprocessing transparency and proven biocompatibility, means that thin films produced in this way will be useful for bioengineers studying the interaction of microand nanodimensioned features with biological specimen, with regard to tissue engineering, for example. (c) 2005 Wiley Periodicals, Inc. J Biomed Mater Res 76A: 781-787, 2006

Key words: poly(lactic acid); nanoembossing; microstructure; nanostructure; biodegradable

\section{INTRODUCTION}

In the decades since their introduction, modern plastics and polymers have become increasingly utilized as a rich source of manufacturing and experimental materials for industry and academia, respectively. For example, the automotive and food packaging industries use plastics, with their unique properties, as an alternative to their inorganic counterparts, such as metals or glass. ${ }^{1}$ Characteristics such as strength, transparency, and deformability, allied to simple manufacturing techniques, make polymers desirable for the production of goods ranging from automobile bumpers to drink bottles. In academia, and especially in the biological sciences, development of polymer-based apparatus, such as lab-on-a-chip devices $^{2}$ or biochips, ${ }^{3}$ continues apace. The same characteristics, advantageous for the production of consumable goods, make polymeric materials useful for

Correspondence to: C. A. Mills; e-mail: cmills@pcb.ub.es Contract grant sponsor: Spanish Ministry of Science and Technology

(c) 2005 Wiley Periodicals, Inc. producing biological apparatus. Optical transparency, structural rigidity/flexibility, disposability, and/or the ability to sterilize the apparatus are major factors for consideration.

However, materials for use in biological applications have requirements other than the need for good physical characteristics. In particular, the material must be biologically compatible: neither adversely affecting the growth of any culturing species, nor changing the surrounding chemical or physical environment in any experimentation. An example of a biocompatible polymer that has previously been used in biological studies, and is gaining a reputation as a useful bioengineering tool, is poly(2-hydroxypropanoic acid), also known as poly(lactic acid) or PLA.

Lactic acid, the PLA monomer, is chiral and hence exists as stereoisomeric D- and L-forms (Fig. 1). ${ }^{4}$ The monomer can be synthesized in two ways: via a petrochemical route, which produces an almost racemic mixture of the two stereoisomers, or via fermentation, which almost exclusively produces the L-form. Furthermore, it has recently been shown that the L-form can be produced naturally, with an $88 \%$ yield and a high optical purity, using Streptococcus bacteria and starch substrates. ${ }^{5}$ This ability to produce one lactic 
<smiles>C[C@@H](O)C(=O)O</smiles>

(b)<smiles>C[C@@H](O)C(=O)O</smiles><smiles>C[C@H](OC(=O)[C@H](C)OC(=O)[C@@H](C)O)C(=O)O</smiles><smiles>FC(F)(F)C(F)(F)C(F)(F)C(F)(F)C(F)(F)C(F)(F)C(F)(F)CC[Si](Cl)(Cl)Cl</smiles>

Figure 1. Chemical structure of the (a) D- and (b) L-forms of lactic acid, the monomer for (c) PLA, and (d) the fluoroalkylsilane antistick coating for the masters, trichloro-(3, 3, 4, $4,5,5,6,6,7,7,8,8$, 8-tridecafluoro-octyl)silane.

acid stereoisomer in high purity introduces the possibility of tailoring the structure of the subsequent polymer and hence controlling its properties, especially with regard to the polymer crystallinity. ${ }^{6}$ Production of highmolecular-weight PLA [Fig. 1(c)] can be achieved by two methods, via a solvent-free distillation process or via a solvent-based direct condensation where an azeotropic distillation is used to remove the water of condensation as the reaction proceeds. ${ }^{7}$ The PLA used in this work is produced using the prior, solvent-free method. Postsynthesis, the PLA can be redissolved in a suitable solvent, normally chloroform, for the production of thin polymer films via a solvent evaporation technique.

PLA can exist in a number of forms, ranging from a transparent, amorphous polymer, with a glass transition temperature $\left(\mathrm{T}_{g}\right)$ of $\sim 60^{\circ} \mathrm{C}$, to increasingly opaque, semicrystalline forms with $\mathrm{T}_{g}$ values up to $180^{\circ} \mathrm{C}$. The physical and optical properties of PLA are described in more depth in the literature. ${ }^{7}$ Besides being biocompatible, PLA is also biodegradable. This is a useful property which can be utilized in vitro, using cultured biological species to break down the polymer, or in vivo, where the cells of the organism decompose the polymer without producing harmful byproducts. In the absence of biological organisms, temperature- and humidity-based decomposition of PLA films, in the presence of ultraviolet (UV) irradiation, has been studied by Copinet et al. ${ }^{8}$ They concluded that polymer breakdown occurred as a result of hydrolysis of the ester linkages within the polymer chains, the rate of decomposition of which can be increased by the introduction of UV or by an increase in temperature.
Potentially, PLA has wide uses within biomedical fields, from implantable medical devices, including screws and pins, to membrane applications, such as wound covers, ${ }^{4}$ and even as an injectable polymer for, for example, lipoatrophy. ${ }^{9}$ The possibility of fabricating structured PLA surfaces, with structures of the dimensions associated with cells or biological macromolecules, is of interest in fields such as cellular engineering. ${ }^{10,11}$ Here, we have used nanoembossing for the production of superficial structures in freestanding PLA sheets, with features ranging from micrometers to hundreds of nanometers. Nanoembossing is the preferred fabrication method to produce these structures because of its excellent resolution, which allows the production of structures with dimensions down to the nanometer range, and replication capabilities, which also points to the possibility of large-area and/or high-volume manufacture. ${ }^{12}$ The advantage of using the nanoembossing system is that the structures that can be produced approach dimensions comparable with biological macromolecules; much smaller than the size of an individual cell. Hence, the effect of local interactions of these structures with a cell surface can be examined. ${ }^{13,14}$

\section{EXPERIMENTAL}

\section{Materials}

Poly(lactic acid) (PURASORB PLDL 95\%-L/5\%-DL copolymer; PURAC, Netherlands), with an inherent viscosity of $6.15 \mathrm{dL} / \mathrm{g}$, has been formed into freestanding thin films by a solvent casting technique. A $5 \% \mathrm{w} / \mathrm{v}$ PLA solution was prepared by dissolving the polymer in chloroform $\left(\mathrm{CHCl}_{3}\right.$; Panreac, Spain) for $48 \mathrm{~h}$. Once fully dissolved, the polymer solution was cast into a Teflon mold and the solvent evaporated at room temperature over another $48 \mathrm{~h}$. This technique provided PLA thin films of $\sim 200-\mu \mathrm{m}$ thickness.

Masters used for producing microstructures in the PLA surface, over areas up to $1 \mathrm{~cm}^{2}$, were designed in-house and fabricated by the Centro Nacional de Microelectrónica (CNM-CSIC; Barcelona). Microstructures were defined using deep reactive ion etching (DRIE) methods in silicon coated with successive layers of silicon oxide $\left(\mathrm{SiO}_{2}\right)$ and nitride $\left(\mathrm{Si}_{3} \mathrm{~N}_{4}\right){ }^{15}$ This gave masters with both positive (where the features are higher than the master surface) and negative (where the features are below the master surface) superficial microstructures. In this way, masters were produced containing features with lateral dimensions down to $1 \mu \mathrm{m}$. Masters for the production of nanostructures in the PLA surface were obtained by modification of these microstructured masters, or by structuring of a pristine $\mathrm{Si}_{3} \mathrm{~N}_{4^{-}}$ coated silicon surface, via direct milling using focussed ion beam (FIB) lithography apparatus (Strata DB235; FEI Co., Netherlands). Masters could be produced using this method with lateral dimensions down to $70 \mathrm{~nm}$, typically over areas up to $1000 \mu \mathrm{m}^{2}$. 
The $\mathrm{SiO}_{2} / \mathrm{Si}_{3} \mathrm{~N}_{4}$ layers were used to prevent adherence problems between the master and the polymer. However, a fluoroalkylsilane monolayer [trichloro-(tridecafluoro-octyl)silane; United Chemical Technologies, USA; Fig. 1(c)] was also added to the masters as an anti-adhesion layer, to assist in eliminating any sticking of the polymer to the master. The master to be functionalized with the silane was first immersed in isopropanol and sonicated for $10 \mathrm{~min}$, before more thorough cleaning was undertaken by immersion in piranha solution $\left(25 \% \mathrm{H}_{2} \mathrm{O}_{2}: 75 \% \mathrm{H}_{2} \mathrm{SO}_{4}\right)$ at $80^{\circ} \mathrm{C}$ for $\sim 10$ min. The master surface was then rinsed thoroughly with ultrapure water, to remove any sulfuric acid residues, before the silane monolayer was added from a solution of the silane $(10 \mathrm{mM})$ in heptane. The masters were immersed in the silane solution for $20 \mathrm{~min}$, after which they were removed and lightly rinsed with ultrapure water, before being baked at $100^{\circ} \mathrm{C}$ for $1 \mathrm{~h}$. Upon removal from the oven, the substrates were briefly sonicated in hexane, to remove any excess silane from the monolayer surface, before use. The silanization method detailed here was found to be sufficient for the nanoembossing; however, a prebake rinse of the surface with hexane could be used to ensure no polymerization of the silane occurs, but care must be taken not to wash off the required monolayer.

\section{Cell culturing}

Osteoblast-like MG63 cells (from ATCC) were used to test the biocompatibility of the PLA surfaces used in this work. The cells were maintained at $37^{\circ} \mathrm{C}$ and $5 \% \mathrm{CO}_{2}$ in complete medium (D-MEM), containing 10\% fetal calf serum (FCS) and $1 \%$ each of L-glutamine, pyruvate, and streptomycin/ penicillin. Squares $\left(4 \mathrm{~mm}^{2}\right)$ of PLA thin-film polymer were placed in well plates and immersed in $0.5 \mathrm{~mL}$ of the complete medium for $24 \mathrm{~h}$. After this time, the medium was replaced with fresh medium and the MG63 cells were seeded at a density of $2 \times 10^{5}$ cells per well plate. The well plates were cultured in triplicate for periods of 1,4 , and 7 days to evaluate cell proliferation, with the medium being changed biweekly.

\section{Nanoembossing}

The nanoembossing was performed using an Obducat nanoimprinter (Obducat AB, Sweden). Freestanding polymer replicas were produced by introducing the PLA into the imprinting system sandwiched between the master and a second piece of the silicon-based material (Fig. 2). The imprinting proceeded upon closing the chamber so that the press was in contact with both the master and the underlying piece of master material. The master-polymer-substrate sandwich was heated to $60^{\circ} \mathrm{C}$, a temperature around that of the $\mathrm{T}_{g}$ of the PLA $\left(\sim 60^{\circ} \mathrm{C}\right)$, before an imprinting force of 3-MPa pressure was applied. After a predetermined embossing time of $600 \mathrm{~s}$, the temperature was reduced to $38^{\circ} \mathrm{C}$, below that of $\mathrm{T}_{g}$, while maintaining the applied force. Upon reaching this temperature, the pressure was released. The master/polymer was then allowed to slowly cool to room

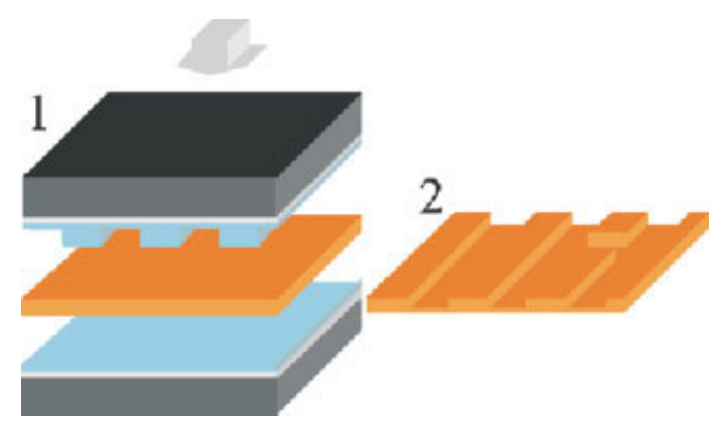

Figure 2. Schematic diagram of the imprinting technique. The PLA is sandwiched between the master and a second piece of the master material (1), which, after imprinting, leaves a freestanding film of the polymer containing the superficial structures (2). [Color figure can be viewed in the online issue, which is available at www.interscience.wiley. com.]

temperature before the master was carefully separated from the polymer. The imprinting parameters could be tweaked as required for optimum replication performance depending on the master used.

\section{Characterization}

Characterization of the surfaces of the masters and the patterned polymers was achieved using white light interferometry (Wyko NT110; Vecco Metrology, USA) and scanning electron microscopy (SEM; Strata DB235, FEI Co., USA). The polymer surfaces were further characterized via contact-angle measurements. Ultrapure water ( $3 \mu \mathrm{L}$; Milli-Q; Millipore, USA) was deposited on the surfaces of the polymer samples using a contact-angle measurement system (OCA 20; Dataphysics, GmbH, Germany), and the advancing contact-angle measured. The water was then removed in $0.5-\mu \mathrm{L}$ aliquots until the drop edge receded and the receding contact angle was measured. Finally, the transparency of the PLA samples was investigated by recording transmission spectra in the visible range of the electromagnetic spectrum, from 700 to $300 \mathrm{~nm}$, using a UV/visible spectrometer (UV2501PC, Shimadzu, Japan). The spectra were recorded with respect to that for air (i.e., a control spectrum with no sample present).

\section{RESULTS AND DISCUSSION}

Optical microscope images of the cells on the surface of unstructured PLA are given in Figure 3. Initially, the seeded cells attach to the PLA surface and start to elongate. After 4 days, the cells have elongated further and begin to form microspikes with which they explore the surrounding environment and attach to the polymer surface. After 7 days, the cells have proliferated successfully and completely cover the surface area of the poly- 

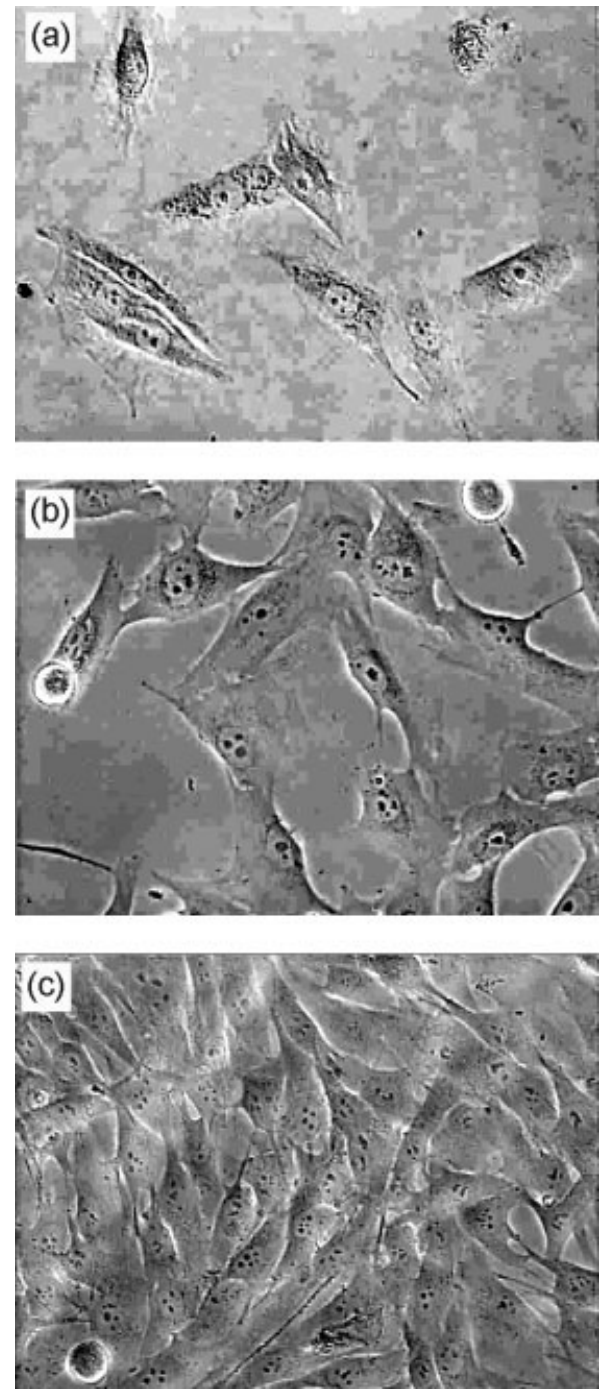

Figure 3. Optical microscope images of the proliferation of MG63 cells, cultured in complete medium (D-MEM), on a pristine PLA surface after (a) 1 day, (b) 4 days, and (c) 7 days.

mer in the image. This proves that the PLA used here can be successfully utilized for culturing MG63 cells.

Figure 4 shows the roughness of the PLA surface produced using the solvent evaporation technique (a), and a PLA surface imprinted, using an unpatterned piece of master material, to produce a flatter polymer surface (b). Figure 4 also gives examples of surfacefeature production in the PLA. Masters containing arrays of square features, with areas of $25 \mu^{2}$ and $\sim 500$ $\mathrm{nm}$ tall/deep [Fig. 4(c,e)], were used to produce structures with complementary dimensions in the surface of freestanding PLA polymer sheets [Fig. 4(d,f)]. Roughness values, taken from the white light interferometry measurements of the masters, the pristine PLA, and the imprinted polymer surfaces, when imaged over areas of $\sim 1 \mathrm{~mm}^{2}$ (Fig. 4), are given in Table I. The surface of the freestanding PLA film, produced using the solvent evaporation method [Fig. 4(a)], is seen from these values to be rougher than PLA imprinted with an unstructured piece of master material [Fig. 4(b)]; it is also rougher than the microstructured PLA surfaces.

Although there was no evidence of adherence problems between the master and the polymer after the imprinting, the images in (d) do suggest some possibility of sticking occurring in localized areas, mainly at the edges of the microstructures. However, the features, using both the positive and negative masters, are faithfully replicated in the PLA over the full area of the patterned surface, and sectional profiles of the replicas confirm that the masters have been imprinted to their full depth. The similar values of the roughness for the masters and their complementary replicas (Table I), also suggest that the PLA has been fully imprinted using this replication technique. The roughness values of the microstructured PLA replicas are typically from 100 to $200 \mathrm{~nm}$, within the range of roughness likely to have an effect on cells cultured on the surface. ${ }^{16}$

The results of the contact-angle measurements are given in Figure 5. The pristine PLA surface is found to have an advancing contact angle of $66^{\circ}$, a receding contact angle of $26^{\circ}$, and consequently produces a wetting hysteresis of $40^{\circ}$. This suggests that the pristine PLA surface is slightly hydrophilic and has a relatively high roughness. Imprinting the PLA with a master with no superficial features produces a polymer surface with an advancing contact angle of $76.5^{\circ}$ (a value closer to that reported in the literature ${ }^{17}$ ), denoting an increase in hydrophobicity, and a wetting hysteresis of $22.5^{\circ}$, indicative of a flatter polymer surface (a conclusion supported by the roughness values in Table I).

Interestingly, upon patterning the PLA surface, using the micropatterned masters, the surface characteristics of the patterned polymer mimic those of the pristine and the imprinted but unstructured surfaces. The PLA remains slightly hydrophilic in both cases, and, as expected because of the increase in the roughness of the micropatterned surfaces, the wetting hysteresis is larger than that for the imprinted but unstructured PLA surface (although the values are comparable with that for the pristine polymer surface). However, the value of the advancing contact angle for the positively microstructured surface $\left(69^{\circ}\right)$ is similar to that for the pristine polymer whereas the value for the negatively microstructured surface $\left(76^{\circ}\right)$ more closely matches that of the imprinted but unstructured surface. This effect is probably dependent on the structure pattern and the surface area of the polymer presented to the water droplet; the surface area of the imprinted features covering $1.25 \times 10^{6}$ and $1.54 \times 10^{6} \mu^{2} \mathrm{~cm}^{-2}$ for the negatively and positively structured PLA, respectively.

Upon imprinting the PLA, the imprinted area becomes more transparent than the pristine PLA. This may be explained as being the result of thinning and flattening of the polymer film during the imprinting process. 

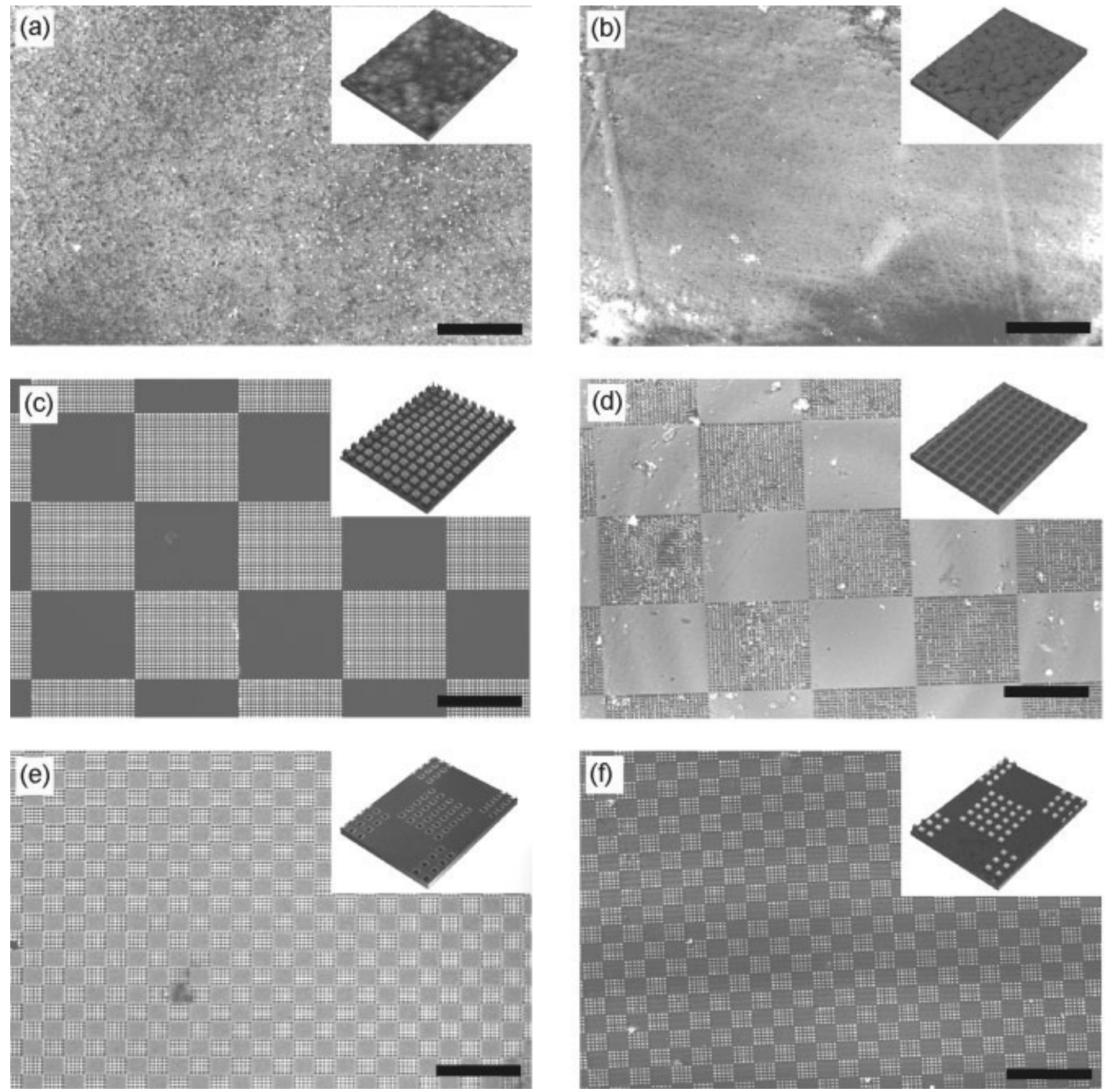

Figure 4. White light interferometric images of pristine and imprinted PLA surfaces and their respective masters. The figures show a large area two-dimensional image of the surface (bar in each case $=20 \mu \mathrm{m}$ ), with (inset) a magnified three-dimensional view of the surface (image area in each case $=94 \times 124 \mu \mathrm{m}$ ). The sections respectively show, (a) a pristine PLA surface, (b) PLA after imprinting using an unstructured piece of master material, (c) a master stamp containing 25- $\mu \mathrm{m}^{2}$, 500-nm-high square posts, (d) the corresponding holes imprinted in a freestanding sheet of PLA, and (e) a master stamp containing $25-\mu \mathrm{m}^{2}, 500-\mathrm{nm}$-deep square holes with (f) the corresponding posts imprinted into a freestanding sheet of PLA. The macropattern in (c) and (d) consists of $250 \times 250 \mu \mathrm{m}$ arrays of the features, which cover a total area of $1 \mathrm{~cm}^{2}$. The macropattern in (e) and (f) consists of $45 \times 45 \mu \mathrm{m}^{2}$ arrays of the features, which again cover a total area of $1 \mathrm{~cm}^{2}$.

TABLE I

Total height $\left(R_{\mathrm{t}}\right)$ and r.m.s. Roughness $\left(R_{\mathrm{q}}\right)$ Values, of the Imprint Masters and the Pristine, Imprinted but Unstructured, and Microstructured PLA, Taken From the Main Interferometry Images in Figure 4

\begin{tabular}{lcc}
\hline \multicolumn{1}{c}{ Surface } & $R_{\mathrm{q}} / \mathrm{nm}$ & $R_{\mathrm{t}} / \mu \mathrm{m}$ \\
\hline Pristine PLA & 349 & 3.94 \\
Imprinted PLA (unstructured) & 16 & 1.06 \\
Negative master & 72 & 3.59 \\
Positive PLA replica & 79 & 3.54 \\
Positive master & 139 & 1.26 \\
Negative PLA replica & 189 & 2.59 \\
\hline
\end{tabular}

Figure 6 shows PLA surfaces imprinted with 500-nmhigh posts, with $25-\mu \mathrm{m}^{2}$ area and $2.5-\mu \mathrm{m}$ diameter, respectively, covering the complete $1-\mathrm{cm}^{2}$ imprinted area. The transparency of these structured films, as well as the pristine PLA sheet and the PLA imprinted with the unstructured master (Fig. 4), was measured in the visible region of the electromagnetic spectrum (Fig. 7).

The pristine PLA film is found to transmit between $10-30 \%$ of the incident light compared with the blank. The microstructured PLA films transmitted a similar amount of light, with the $2.5-\mu \mathrm{m}$-diameter posts transmitting slightly more of the incident light than the other two samples. The low transmittance of these films is probably the result of scattering of the incident light by 


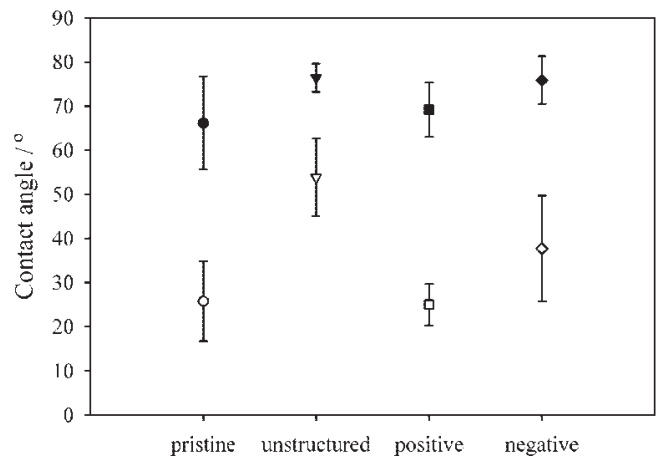

Figure 5. Contact-angle measurements of the surfaces of pristine $(\bullet)$, imprinted but unstructured $(\boldsymbol{\nabla})$, positively $(\boldsymbol{\square})$, and negatively $(\diamond)$ microstructured PLA. Average advancing (filled symbols) and receding (open symbols) contact angles are given, for six measurements on each surface, using $3-\mu \mathrm{L}$ drops of water. The difference between the advancing and receding values gives the wetting hysteresis, which provides an indication of the roughness of the surface.

the rough/structured polymer surfaces. In contrast, the imprinted but unstructured PLA film is seen to transmit up to $80 \%$ of the incident light at the red end of the measurement range (although this falls to 30\% toward the UV end of the spectrum). This suggests that unstructured, or lightly structured (as in the case of fluidics), PLA films could be used for biological applications where standard optical microscopes are required, for imaging cells, etc., on the polymer surface.

Presumably, the polymer becomes stressed during the imprinting, and the elevated pressure and temperature therefore causes the polymer to become increasingly crystalline. Although this may cause the polymer film to lose some flexibility, advantages to a stress-induced crystalline PLA structure include a higher strength and increased chemical resistance. $^{7}$

Examples of the versatility of using nanoembossing for structuring PLA surfaces are given in Figure 8, which shows the polymer with structures in the hundreds-of-

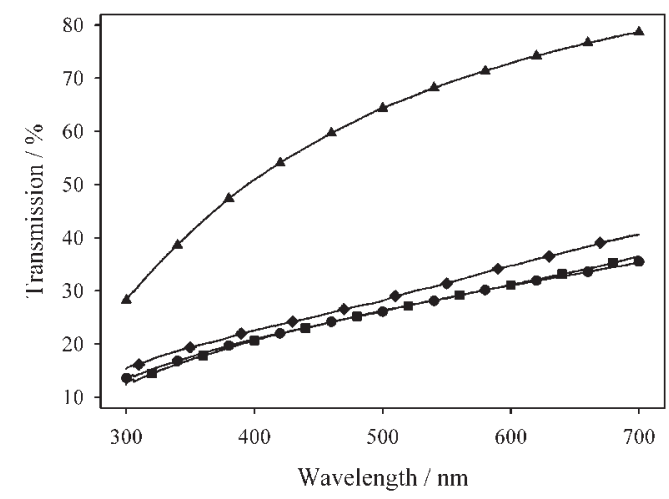

Figure 7. UV/visible transmission measurements for thin films of pristine PLA $(\bullet)$, imprinted but unstructured PLA $(\boldsymbol{\nabla})$, and PLA containing the $25-\mu \mathrm{m}^{2}(\boldsymbol{\square})$ and $2.5-\mu \mathrm{m}$-diameter $(\checkmark)$ microstructures shown in Figure 6.

nanometers range. Circular posts, $500 \mathrm{~nm}$ tall and 500 $\mathrm{nm}$ diameter, have been imprinted on a PLA surface, within a channel $40 \mu \mathrm{m}$ wide and $500 \mathrm{~nm}$ deep [Fig. $8(a)]$. These posts can be used to interact with cells at a local scale or, if the channel can be sealed, the posts can be used within a fluidic system as a filter or a separator. Figure $8(\mathrm{~b})$ shows the ends of a set of lines, $100 \mu \mathrm{m}$ long, $200 \mathrm{~nm}$ wide, $200 \mathrm{~nm}$ tall, and with a period of $1 \mu \mathrm{m}$. These line structures could be used for structuring cells in applications such as tissue engineering, for example. The superficial structuring of the polymer surface can be used to direct the growth of the cells in a certain direction (usually along the direction of the lines) and act as a biodegradable scaffold for tissue formation.

These biocompatible, micro- and nanopatterned PLA surfaces could be useful for polymer-cell interaction experiments at dimensions at, or below, that of individual cells. Indeed, postfabrication modification of the microstructured PLA surface, with materials such as collagen ${ }^{17}$ (which can further reduce the hydrophobicity of the surface), will extend the range of applications, possibly through the
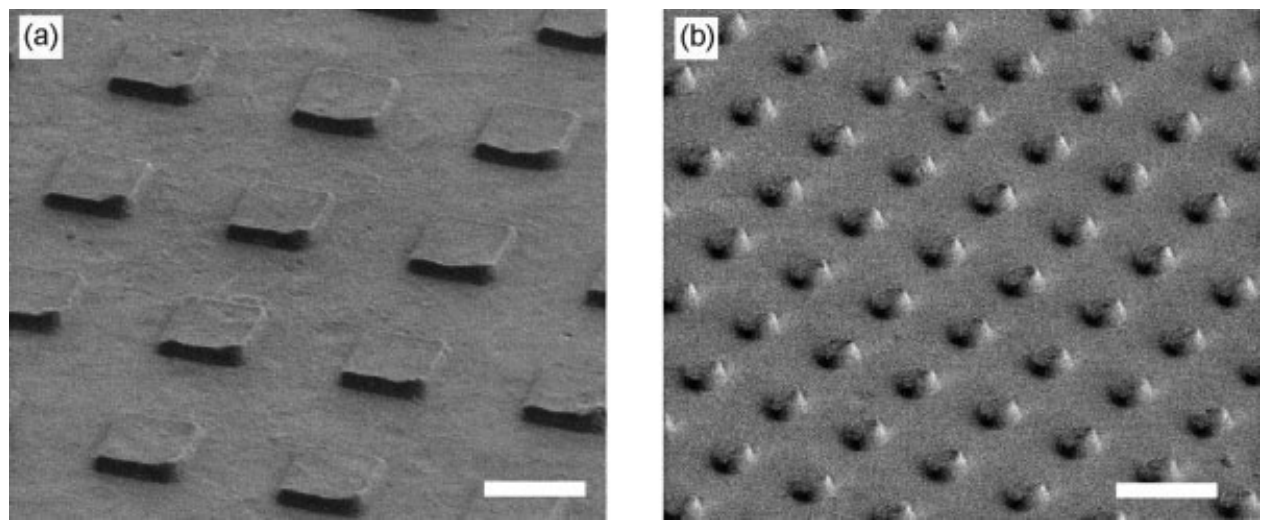

Figure 6. SEM images of (a) $25-\mu \mathrm{m}^{2}, 500-\mathrm{nm}$-tall square posts with a $10-\mu \mathrm{m}$ period $(\mathrm{bar}=5 \mu \mathrm{m})$ and (b) $2.5-\mu \mathrm{m}$ diameter, $500-\mathrm{nm}$-tall round posts with a $5-\mu \mathrm{m}$ period $(\mathrm{bar}=5 \mu \mathrm{m})$ nanoimprinted into a freestanding sheet of PLA. In each case, the posts cover the full $1 \mathrm{~cm}^{2}$ of the stamped area. 

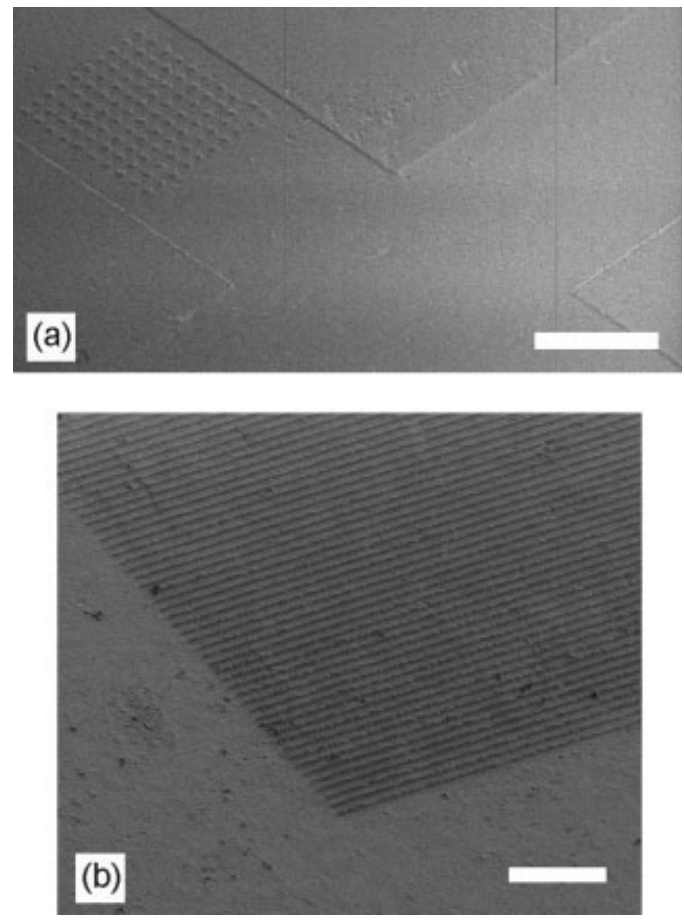

Figure 8. SEM images of examples of some further structures of micro/nanostructured PLA. (a) Posts $500 \mathrm{~nm}$ in diameter and $500 \mathrm{~nm}$ tall contained within a channel $40 \mu \mathrm{m}$ wide and $500 \mathrm{~nm}$ deep for use in microfluidics (bar $=20$ $\mu \mathrm{m})$, and (b) lines $200 \mathrm{~nm}$ wide, $200 \mathrm{~nm}$ tall, and $100 \mu \mathrm{m}$ in length (not fully imaged) with a period of $1 \mu \mathrm{m}$, for use in the directional culturing of cells (bar $=10 \mu \mathrm{m}$ ).

use of PLA's inherent biodegradability. Further study is being undertaken to examine whether these structures promote cell growth on the polymer surface. If superficial structures with different geometries are found to increase or decrease cell adhesion or proliferation, when compared with unstructured surfaces, the ability to use PLA within the body ${ }^{18}$ suggests that these micropatterned surfaces could be used as biodegradable scaffolds in such applications as tissue repair. ${ }^{16}$

The authors thank J. Bausells and G. Villanueva at the National Centre for Microelectronics (CNM), Barcelona, for providing the $\mathrm{Si} / \mathrm{Si}_{3} \mathrm{~N}_{4}$ masters used here and also to Drs. F. Bessueille and M. Pla-Roca of the Barcelona Science Park for the silanization of the masters. Thanks also go to Dr. D. Lacroix, Dr. G. Gomila, and A. Samso of the Barcelona Science Park for invaluable discussions during the production of this work. C. A. Mills, E. Martinez, and A. Errachid acknowledge support from the Spanish Ministry of Science and Technology via the Ramon y Cajal program.

\section{References}

1. de Mello A. Plastic fantastic? Lab Chip 2002;2:31N-36N.

2. Becker H, Locascio LE. Polymer microfluidic devices. Talanta 2002;56:267-287.

3. Kricka LJ. Microchips, microarrays, biochips and nanochips: personal laboratories for the 21st century. Clin Chim Acta 2001;307:219-223.

4. Bendix D. Chemical synthesis of polylactide and its copolymers for medical applications. Polym Degrad Stab 1998;59:129-135.

5. Narita J, Nakahara S, Fukuda H, Kondo A. Efficient production of L-(+)-lactic acid from raw starch. J Biosci Bioeng 2004;97:423-425.

6. Kolstad J. Crystallization kinetics of poly(L-lactide-co-mesolactide). J Appl Polym Sci 1996;62:1079-1091.

7. Lunt J. Large-scale production, properties and commercial applications of polylactic acid polymers. Polym Degrad Stab 1998;59:145-152.

8. Copinet A, Bertrand C, Govindin S, Coma V, Courturier Y. Effects of ultraviolet light $(315 \mathrm{~nm})$, temperature and relative humidity on the degradation of polylactic acid plastic films. Chemosphere 2004;55:763-773.

9. SCULPTRA ${ }^{\mathrm{TM}}$ (injectable poly-L-lactic acid). Bridgewater, NJ: Aventis Pharmaceuticals.

10. Curtis A, Wilkinson C. Topographical control of cells. Biomaterials 1997;18:1573-1583.

11. Wilkinson CDW, Riehle M, Wood M, Gallagher J, Curtis ASG The use of materials patterned on a nano- and micro-metric scale in cellular engineering. Mater Sci Eng C 2002;14:263-269.

12. Sotomayor-Torres CM, Zankovych S, Seekamp J, Kam AP, Clavijo Cedenõ C, Hoffmann T, Ahopelto J, Reuther F, Pfeiffer K, Bleidiessel G, Gruetzner G, Maximov MV, Heidari B. Nanoimprint lithography: an alternative nanofabrication approach. Mater Sci Eng C 2003;23:23-31.

13. Dalby MJ, Giannaras D, Riehle MO, Gadegaard N, Affrossman S, Curtis ASG. Rapid fibroblast adhesion to $27 \mathrm{~nm}$ high polymer demixed nano-topography. Biomaterials 2004;25:77-83.

14. Vance RJ, Millar DC, Thapa A, Haberstroh KM, Webster TJ Decreased fibroblast cell density on chemically degraded polylactic-co-glycolic acid, polyurethane, and polycaprolactone. Biomaterials 2004;25:2095-2103.

15. Mills CA, Martinez E, Besueille F, Villanueva G, Bausells J, Samitier J, Errachid A. Production of structures for microfluidics using polymer imprint techniques. Microelectron Eng 2005;78-79:695-700.

16. Wilkinson CDW, Curtis ASG, Crossan J. Nanofabrication in cellular engineering. J Vac Sci Technol B 1998;16:3132-3136.

17. Zhu Y, Gao C, Liu Y, Shen J. Endothelial cell functions in vitro cultured on poly(L-lactic acid) membranes modified with different methods. J Biomed Mater Res 2004;69A:436-443.

18. McGuire DA, Barber FA, Milchgrub S, Wolchok JC. A postmortem examination of poly-L-lactic acid interference screws 4 months after implantation during anterior cruciate ligament reconstruction. Arthroscopy 2001;17:988-992. 